\title{
Tumor neuroectodérmico primitivo renal/Sarcoma de Swing
}

\author{
E. Mallén Mateo, C. Sancho Serrano, D. Pascual Regueiro, A. García de Jalón Martínez, \\ M.J. Gil Sanz, A. Gonzalvo Ibarra, L.A. Rioja Sanz
}

Servicio Urología. Hospital Miguel Server. Zaragoza.

Actas Urol Esp 2005; 29 (3): 311-313

\section{RESUMEN}

TUMOR NEUROECTODÉRMICO PRIMITIVO RENAL. SARCOMA DE EWING

Los tumores neuroectodérmicos primitivos de riñón son neoplasias extremadamente raras, pudiendo ser confundidas con toda la variedad de tumores de células redondas de riñón. Es importante hacer diagnóstico diferencial entre estas entidades por sus implicaciones terapéuticas y pronosticas, aunque no deja de ser difícil debido a su infrecuencia.

Estos tumores son extremadamente agresivos, con tendencia a la recurrencia y a la diseminación temprana a distancia. El tratamiento combina cirugía, quimioterapia y radioterapia, apoyándose en la terapia génica.

Aportamos un caso de tumor neuroectodérmico primitivo de riñón en una paciente de 50 años.

Palabras clave: Riñón.Tumor neuroectodérmico primitivo. Sarcoma de Ewing.

\section{ABSTRACT}

PRIMITIVE NEUROECTODERMAL TUMOR. EWING'S SARCOMA

Primitive neuroectodermal tumor is an extraordinarily rare primary tumor in the kidney and can be mistaken for a variety of other round cell tumors.It is important to recognize each of these entities, because each carries unique therapeutic and prognostic implications. However, accurate diagnosis of these tumors is hindered by their significant morphologic overlap and complicated by their rarity.

These neplasm are highly aggressive that tend to recurence and to metastatize. Standard therapy combining surgery, chemotherapy, radiation and genetic therapy.

We report a case of primitive neuroectodermal tumor of the kidney in a 50 year old female patient.

Keywords: Kidney. Primitive neuroectodermal tumor. Ewing’s Sarcoma.

$\mathrm{B}^{\mathrm{a}}$ ajo el término de tumores neuroectodérmicos primitivos de riñón se incluye a un grupo heterogéneo de entidades patológicas, formadas por células redondeadas de pequeño tamaño, como tumor de Wilms, linfoma, sarcoma de células claras, carcinoma de células pequeñas, neuroblastoma o el sarcoma de Ewing ${ }^{1}$.

Estos últimos, pertenecen al grupo de tumores neuroectodérmicos primarios periféricos malignos que representan el $1,1 \%$ de tumores de partes blandas dentro de la población general. El riñón es la localización visceral más frecuente, con tendencia a la recurrencia local y a metastatizar a distancia ${ }^{2}$.

En general, presentan mal pronóstico, pero es importante reconocer cada uno del conjunto de estas neoplasias, por su implicación terapéutica.
El estudio de factores predictivos pronósticos, morfológicos, como genéticos y de biología molecular tienen su importancia ${ }^{3}$.

\section{CASO CLÍNICO}

Mujer de 50 años de edad, sin ningún antecedente clínico ni urológico de interés.

Ante un cuadro de molestias lumbares izquierdas, de unas tres semanas de evolución, sin presencia de hematuria, y con una exploración física anodina se realizó ecografía. Con el hallazgo de masa renal izquierda, se continuó estudio con TAC. En este último se confirmó voluminosa masa encapsulada en polo medio de riñón izquierdo, de $8 \times 12 \mathrm{~cm}$, de densidad heterogénea. Sin observar adenopatías. En los estudios analíticos, todos los parámetros se encontraban en rangos dentro de la normalidad. La radiografia de tórax fue normal. 
Con el diagnóstico de masa renal izquierda se realiza nefrectomía radical izquierda, intraoperatoriamente se observa gran masa renal dependiente de polo superior, sin observar adenopatías. El curso postoperatorio transcurrió sin incidentes.

El estudio anatomopatológico confirmaba macroscópicamente, pieza de nefrectomía izquierda de 247 g. Externamente se observaba una tumoración de 5x6x4 cm que rompía la cápsula. Al corte, tumoración blanquecina, con áreas pardas de localización central, extendiéndose hacia la periferia (Fig. 1).

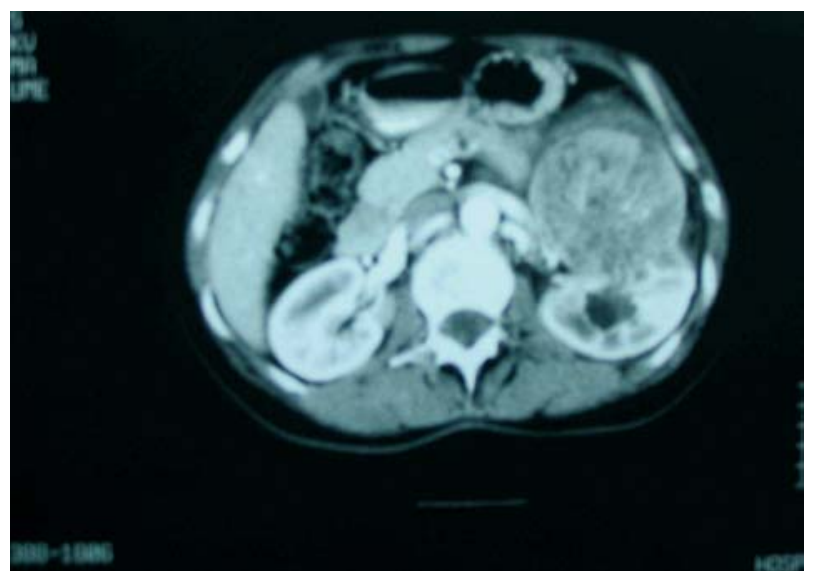

FIGURA 1. TAC: voluminosa masa renal izquierda, de $8 x$ $12 \mathrm{~cm}$, heterogénea, con extensos focos hipodensos que sugieren necrosis.

El estudio microscópico describía tumor renal formado por láminas de células pequeñas, monoformas con núcleos redondeados de cromatina fina y moderado índice mitótico. Con citoplasma escaso, claro o eosinófilo. Se observaban extensas áreas de necrosis con conservación en áreas de las células perivasculares, dando una imagen pseudopapilar (Fig. 2).

En el estudio inmunoestoquímico se demostró positividad para vimentina y 013 (CD-99). Negatividad para Queratinas (CK7, CK20, AE1AE3, 34 beta E12) ALC, desmina, cromogranina, sinaptofisina, CD34, CD31, c-kit, actina, EMA y S100. Ki 67: bajo índice proliferativo (Tabla I).

El diagnóstico definitivo fue tumor neuroectodérmico primitivo de riñón de localización predominantemente medular que rompe cápsula renal e invade tejido adiposo perirrenal.

Se completo el estudio con rastreo óseo y PECT, siendo ambos normales. Asímismo se realizó biopsia de médula ósea sin hallar alteraciones celulares a este nivel. Con dicho diagnós-

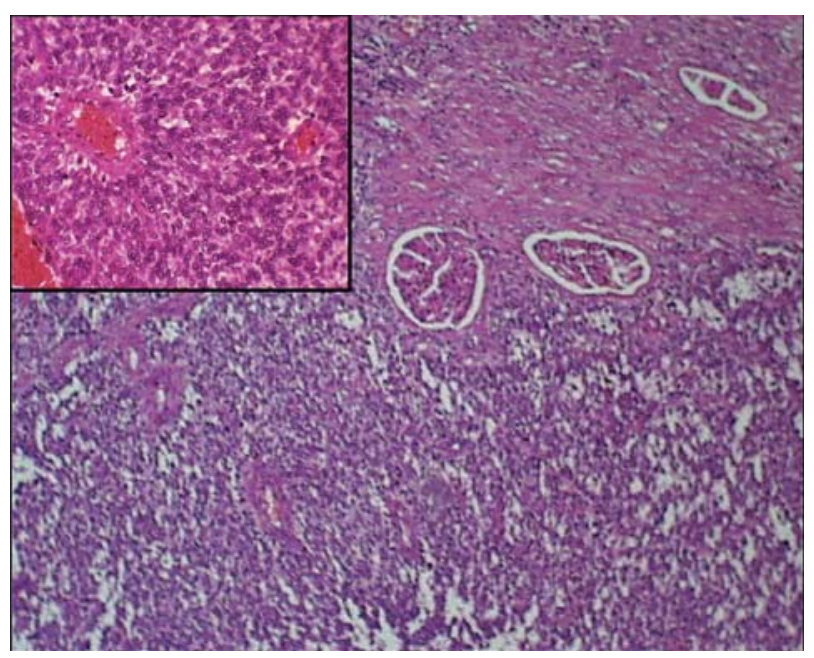

FIGURA 2. Infiltración del parénquima renal por una proliferación difusa de células de talla pequeña. (HE 100x). En detalle, a mayor aumento, se observan las caracteristicas microscópicas: células de talla pequeña con núcleos redondeados, monomorfos y citoplasma escaso.

tico se inició tratamiento quimioterápico por parte del servicio de Oncología. Siguiendo el esquema VAC-IE alternante (Vincristina, Adriamicina, Ciclofosfamida alternando con fosfamida y etopósido) hasta completar cuatro ciclos, con intención de administrar Radioterapia, una vez finalizado el tratamiento quimioterápico.

A los seis meses de la nefrectomía la paciente se encuentra asintomática y con un estado general aceptable.

\section{DISCUSIÓN}

Los tumores de células pequeñas de riñón comprenden a un grupo diverso de neoplasias, dentro de la inusualidad de los mismos debemos destacar a los linfomas renales como los más frecuentes. Sin embargo, deben incluirse en este grupo además el tumor de Wilms, el sarcoma de células claras, el carcinoma de células pequeñas, neuroblastoma o el sarcoma de Ewing ${ }^{1}$.

Tabla 1

\begin{tabular}{|c|c|c|}
\hline & Positividad & Negatividad \\
\hline Cromogranina & & $\checkmark$ \\
\hline Sinaptofisina & & $\checkmark$ \\
\hline CD34 & & $\checkmark$ \\
\hline CD31 & & $\checkmark$ \\
\hline c-kit & & $\checkmark$ \\
\hline Actina & & $\checkmark$ \\
\hline EMA & & $\checkmark$ \\
\hline $\mathrm{S} 100$ & & $\checkmark$ \\
\hline Vimentina & $\checkmark$ & \\
\hline CD99 & $\checkmark$ & \\
\hline
\end{tabular}

Tabla donde se muestra el estudio inmunohistoquímico. 
Estos últimos, son excepcionales y pertenecen al grupo de tumores neuroectodérmicos primarios periféricos malignos. El primer caso de localización en aparato genitourinario fue descrito en 1975 por Bennington ${ }^{1,4}$ y la serie más larga publicada se debe a Parham et al con 79 casos $^{5}$.

En nuestro caso se trata de una mujer de mediana edad, 50 años pero suele presentarse en jóvenes adultos ( $2^{\mathrm{a}}-3^{\mathrm{a}}$ década), con un ligero predominio en el sexo femenino según las series.

Los PNT renales son tumores agresivos, el 25$50 \%$ de los pacientes presentan metástasis en el momento del diagnóstico y una tasa libre de enfermedad a los 5 años del 45-55\% pese al uso de la cirugia, radioterapia y quimioterapia agresiva ${ }^{6}$.

Representa uno de los tumores más indiferenciados histológicamente, son varias las hipótesis histogénicas barajadas. Parece existir concordancia para aceptar que las células redondas y pequeñas derivarian de la cresta neural y tendrían un carácter neuroectodérmico. Ello va a conllevar a una diversidad histológica y a una expresión genética compleja, traduciéndose en una clínica variada y un pronóstico infausto ${ }^{3}$.

El diagnóstico anatomopatológico no es fácil, el estudio histológico básico del tumor presenta células de núcleo redondo, citoplasma escaso, dispuestas en nidos o láminas formando en ocasiones rosetas de Homer-Wright (sugerentes de diferenciación neural). La invasión de la cápsula y la extensión a la grasa perirrenal suele ser la norma en más de la mitad de los casos. La tasa de proliferación en general es media y las áreas de necrosis son frecuentes ${ }^{2}$.

Como complemento para el diagnóstico disponemos de la inmunohistoquímica. Los PNET renales, demuestran positividad a marcadores de la linea neural, tales como vimentina, S100, e incluso algunas queratinas. Existe un marcador que lo define, aunque no es específico, el CD99; glicoproteína de membrana de 30/32 $\mathrm{kDa}$ de peso molecular, producto de la expresión del gen MIC2, detectado con los Ac.013 y 12E7².

La citogenética tiene también especificidad para su diagnóstico y es la presencia de una traslocación cromosómica (11:22 ;q 24, q 12). Fue descrita en 1983, por Aurias y col, y se encuentra presente en un gran número de tumores neuroectodérmicos primitivos renales $^{3}$. Esta traslocación lleva a la fusión del gen del S. de Ewing, ubicado en el cromosoma 22, a un gen FLI 1, ubicado en el cromosoma 11, produciendo transcripción de información quimérica $^{1}$.
Estudios mediante PCR-RT han confirmado que el transcripto de fusión EWS / FLI-1 está presente en el 85\% de los casos. También se han encontrado otras variantes menos frecuentes como $t(21 ; 22)$ (q22 ;q12).2 En nuestro caso no se pudo realizar dicha técnica al no disponer de tejido fresco. Autores como Kumar et al. refieren técnicas que permiten describir con seguridad la fusión EWS / FLI-1 a partir de material fijado, estas técnicas aún no están generalizadas ${ }^{2,7}$.

Ante el diagnóstico de este tumor, orientado primeramente por la microscopía, complementado con la inmunohistoquímica, hay que hacer diagnóstico diferencial con neuroblastoma, tumor de Wilms, rabdomiosarcoma, linfoma, sarcoma de células claras, nefroma mesoblástico etc indudablemente, los datos clínicos y epidemiológicos nos servirán de gran ayuda.

En cuanto al tratamiento, la nefrectomía radical suele preceder al diagnóstico histológico. Ésta suele complementarse con quimioterapia y radioterapia en la recidivas locales ${ }^{2,6}$.

Hay autores que proponen una terapia génica específica para este grupo de tumores, basándose en la creación de oligonucleótidos complementarios (antisentido) para el transcripto de fusión anómalo. Impidiendo así la formación de proteínas anómalas, responsable de la activación de la transcripción del $\mathrm{DNA}^{8}$

\section{REFERENCIAS}

1. Gonzalo Valero F, Arturo Escaloa L, Rodrigo Leyton N. Tumor neuroectodérmico primitivo del riñón. Caso Clínico. Rev Méd Chile 2001;129

2. Cuesta Alcalá JA, Solchaga Martínez A, Caballero Martínez MA, et al Tumor neuroectodérmico primitivo renal (PNET): 26 casos. Estado actual de su diagnóstico y tratamiento. Arch Esp Urol 2001;54:1081-1093.

3. Llombart-Bosch A. IV Congreso virtual hispanoamericano de anatomía patológica

4. Bennington JC, Beckwith SB.Tumors of the kidney, renal pelvis and ureter. In: Atlas of TumorWashington DC: Armed Forces Institute of Pathology, 2nd series, fasc. 12;197.:289

5. Parham D, Roloson G, Feely M, et al. Primary Malignant Neuroepithelial Tumors of the Kidney. Am J Surg Pathol 2001; 25:133-146.

6. Jiménez R, Folpe A, Laphamr, et al. Primary Ewing’s Sarcoma/Primitive Neuroectodermal Tumor of the Kidney. Am J Surg Pathol 2002; 26:320-327.

7. Kumar S, Pack S, Kumar D, Walker R, Quezado M, Zhuang Z, Meltzer P, Tsokos M. Detection of EWS-FLI-1 fusion in Ewing's sarcoma/peripheral primitive neuroectodermal tumor by fluorescence in situ hybridization using formaling-fixed paraffin-embedded tissue. Hum Pathol 1999;30(3): 324-330.

8. Deramaudt, B.M., Remy, P., Abraham, N.G.: Upregulaction of human heme-oxygenase gene expression by Ets-family proteins. J. Cell Biochem 1999 1;72(3):311-321.

Dra. E. Mallén Mateo

San Antonio Mํㅡㄹ Claret, 66 - 2 I

50005 Zaragoza

(Trabajo recibido el 15 junio de 2004) 